\title{
Hepcidin overexpression in astrocytes alters brain iron metabolism and protects against amyloid- $\beta$ induced brain damage in mice
}

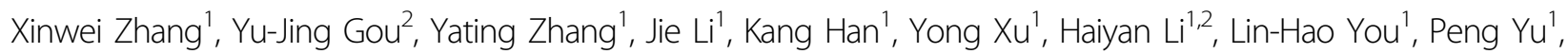
Yan-Zhong Chang ${ }^{1}$ and Guofen Gao ${ }^{1}$

\begin{abstract}
Progressive iron accumulation in the brain and iron-induced oxidative stress are considered to be one of the initial causes of Alzheimer's disease (AD), and modulation of brain iron level shows promise for its treatment. Hepcidin expressed by astrocytes has been speculated to regulate iron transport across the blood-brain barrier (BBB) and control the whole brain iron load. Whether increasing the expression of astrocyte hepcidin can reduce brain iron level and relieve AD symptoms has yet to be studied. Here, we overexpressed hepcidin in astrocytes of the mouse brain and challenged the mice with amyloid- $\beta_{25-35}\left(A \beta_{25-35}\right)$ by intracerebroventricular injection. Our results revealed that hepcidin overexpression in astrocytes significantly ameliorated $A \beta_{25-35}$-induced cell damage in both the cerebral cortex and hippocampus. This protective role was also attested by behavioral tests of the mice. Our data further demonstrated that astrocyte-overexpressed hepcidin could decrease brain iron level, possibly by acting on ferroportin 1 (FPN1) on the brain microvascular endothelial cells (BMVECS), which in turn reduced $A \beta_{25-35}$-induced oxidative stress and apoptosis, and ultimately protected cells from damage. This study provided in vivo evidences of the important role of astrocyte hepcidin in the regulation of brain iron metabolism and protection against $A \beta$-induced cortical and hippocampal damages and implied its potential in the treatment of oxidative stress-related brain disorders.
\end{abstract}

\section{Introduction}

Iron plays vital roles in various physiological activities in the brain, including oxygen transport, DNA synthesis, mitochondrial respiration, myelination, neurotransmitter synthesis, and so on ${ }^{1,2}$. However, through the Fenton reaction, excessive iron can induce the generation of reactive oxygen species (ROS) that is damaging to the cells ${ }^{1,3}$.

Accumulating evidences from human and animal models have indicated a close association between iron

\footnotetext{
Correspondence: Yan-Zhong Chang (chang7676@163.com) or Guofen Gao (guofen83@hotmail.com)

${ }^{1}$ Laboratory of Molecular Iron Metabolism, College of Life Sciences, Hebei Normal University, No. 20, Nan Er Huan East Road, 050024 Shijiazhuang, China ${ }^{2}$ Chengde Medical University, Shuang Qiao District, An Yuan Road, 067000 Chengde, China

These authors contributed equally: Xinwei Zhang, Yu-Jing Gou Edited by Ivano Amelio
}

dysregulation and the pathogenesis of Alzheimer's disease $(A D)^{4,5}$. It has been demonstrated that iron heavily accumulated in amyloid- $\beta$ (A $\beta$ ) plaques and neurofibrillary tangles of the AD brain ${ }^{5-7}$, where it participated in redox cycling and led to oxidative damage ${ }^{4,8,9}$. In addition, the expressions of iron transporters and iron regulatory proteins were dysregulated in $\mathrm{AD}^{10-13}$. Modulation of the brain iron level or its metabolism to maintain brain iron homeostasis has been considered to be a promising therapy for $\mathrm{AD}^{4,14-16}$.

Hepcidin is the major regulator of systemic iron homeostasis ${ }^{17}$. Hepcidin binds to the iron exporter ferroportin 1 (FPN1) on the cell membrane, leading to FPN1 degradation and resulting in the reduction of iron release from the target cells ${ }^{18}$. In the peripheral system, hepcidin secreted by hepatocytes strictly regulates the transport of iron in intestinal and duodenal cells, thus maintaining the

\section{(c) The Author(s) 2020}

(c) (i) Open Access This article is licensed under a Creative Commons Attribution 4.0 International License, which permits use, sharing, adaptation, distribution and reproduction in any medium or format, as long as you give appropriate credit to the original author(s) and the source, provide a link to the Creative Commons license, and indicate if changes were made. The images or other third party material in this article are included in the article's Creative Commons license, unless indicated otherwise in a credit line to the material. If material is not included in the article's Creative Commons license and your intended use is not permitted by statutory regulation or exceeds the permitted use, you will need to obtain permission directly from the copyright holder. To view a copy of this license, visit http://creativecommons.org/licenses/by/4.0/. 
balance of the systemic iron level ${ }^{19,20}$. In the brain, hepcidin is widely distributed in neurons, glial cells, and vascular endothelia at blood-brain barrier (BBB) in various regions ${ }^{21-23}$. It has been reported that hepcidin expression was significantly reduced in hippocampi of $A D$ patients and mouse models along with iron deposition ${ }^{24}$. However, the specific role of hepcidin in $\mathrm{AD}$ and targeting of hepcidin for $\mathrm{AD}$ treatment have not been reported.

Great progress has been made to understand the role of hepcidin in brain iron metabolism ${ }^{25}$. Injection of hepcidin expression adenovirus significantly reduced brain iron in rats and suppressed transport of transferrin-bound iron from the periphery into the brain ${ }^{26}$. Studies have also shown that hepcidin could protect neurons from heminmediated injury ${ }^{27}$, and the hepcidin level was closely associated with neurological inflammatory responses ${ }^{28,29}$. Besides, the expression amount and regional distribution patterns of hepcidin were age-dependent ${ }^{30}$. These findings suggested that a high level of hepcidin could reduce iron overload in the brain, which might be a potentially valuable target for AD treatment. Moreover, it has been proposed that hepcidin secreted by astrocytes could regulate FPN1 on brain microvascular endothelial cells (BMVECs), inducing the internalization and degradation of FPN1, and thus control iron transport across the $\mathrm{BBB}^{31-33}$. Therefore, increasing the expression of hepcidin in astrocytes might reduce brain iron intake and provide a good strategy for reducing the deposition of brain iron and alleviating the symptoms of AD.

In this study, we pre-overexpressed hepcidin in astrocytes of mouse brain and then challenged mice with $\mathrm{A} \beta_{25-35}$ peptide, a peptide widely used to induce $\mathrm{AD}$ symptoms in mice and rats ${ }^{34-36}$. The effects of hepcidin overexpression in astrocytes on $A \beta_{25-35}$-induced damage in the cortex and hippocampus of the mouse brain were investigated. We demonstrated for the first time with in vivo evidences that astrocyte hepcidin could modulate brain iron metabolism and prevent iron overload in the brains of $A \beta$-treated mice, and therefore exhibit a protective effect against $A \beta_{25-35}$-induced oxidative damage and apoptosis.

\section{Results}

\section{Astrocyte-specific overexpression of hepcidin protected against $A \beta$-induced cognitive decline in mice}

To overexpress hepcidin in astrocytes of mouse brain, we constructed a pAAV-gfap:Hamp plasmid with mouse hepcidin gene (Hamp) under the control of astrocytespecific GFAP promoter. To confirm its expression efficacy and astrocyte specificity, mice were administrated with this plasmid or the vector control by intracerebroventricular (ICV) injection. qRT-PCR analysis revealed increased hepcidin mRNA levels in the cerebral cortex and hippocampus of mice injected with Hamp plasmid, and immunofluorescence staining indicated good specificity for astrocytes (Fig. 1a, b).

To investigate the role of astrocyte hepcidin overexpression in $\mathrm{A} \beta$-induced brain damage, we injected mice with $A \beta_{25-35}$ peptide after hepcidin overexpression ${ }^{35,36}$. The spatial learning and memory abilities of mice in different groups were assessed by MWM test after 1 week (Fig. 1c). Compared with the mice without $A \beta$ treatment (control group), $A \beta$-treated mice ( $A \beta$ group) displayed a significant learning and memory decline, as indicated by the longer escape latency time during training (Fig. 1d), the lower number of times passing over the target zone (Fig. 1e), and the shorter time spent in the target quadrant after removing the platform (Fig. 1f). Strikingly, the mice pre-injected with Hamp and then injured by $\mathrm{A} \beta$ (Hamp $+\mathrm{A} \beta$ group) showed significantly improved learning and memory abilities compared with the mice in $A \beta$ group. The Hamp $+A \beta$ mice exhibited better escape latency to the platform at day 4 and day 5 compared with $A \beta$ mice (Fig. 1d, indicated by \#), and also crossed the platform area more times after removing the platform (Fig. 1e). The hepcidin expression in the brain of different groups of mice was assessed by western blot. As shown in Fig. 1g-i, the Hamp and Hamp $+\mathrm{A} \beta$ groups showed significantly higher levels of hepcidin than the control and $A \beta$ groups, respectively, in both the cortex and hippocampus regions. The $A \beta$ group showed a higher level of hepcidin than the control group, indicating that the $\mathrm{A} \beta_{25-35}$ peptide triggered inflammatory responses and induced hepcidin expression ${ }^{19}$.

In addition, we examined the levels of postsynaptic density protein-95 (PSD-95) in the hippocampus of different mice ${ }^{37}$. The results showed that PSD-95 mRNA and protein expression was reduced in the $A \beta$ group compared to the control group, while astrocyte hepcidin overexpression rescued this reduction (Supplementary Fig. S1). These results suggest that the overexpression of hepcidin in astrocytes significantly alleviates learning and memory deficits in the A $\beta$-induced AD model.

\section{Astrocyte-specific overexpression of hepcidin alleviated $A \beta$-induced apoptosis}

The trigger of apoptosis by $A \beta_{25-35}$ peptides was reported previously ${ }^{36}$. The damage induced by $A \beta_{25-35}$ was specific as compared to $A \beta_{35-25}$ control peptide, and the apoptotic cells included both neurons and glial cells (Supplementary Fig. S2). We assessed the apoptotic levels in the cortex and hippocampus of different mice by TUNEL staining. It was found that $A \beta_{25-35}$ treatment induced a large number of apoptotic cells in the cortex and CA3 region of the hippocampus (Fig. $2 \mathrm{a}-\mathrm{C}$ ). Interestingly, overexpression of hepcidin in astrocytes and subsequent administration of $A \beta_{25-35}$ resulted in a visible decrease in apoptotic cells in both the cortex and hippocampus (Fig. 2a-c). The contents 


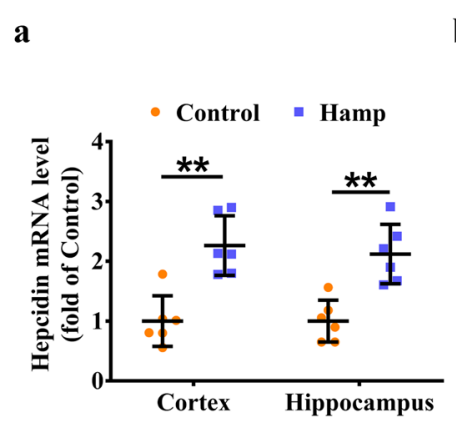

b
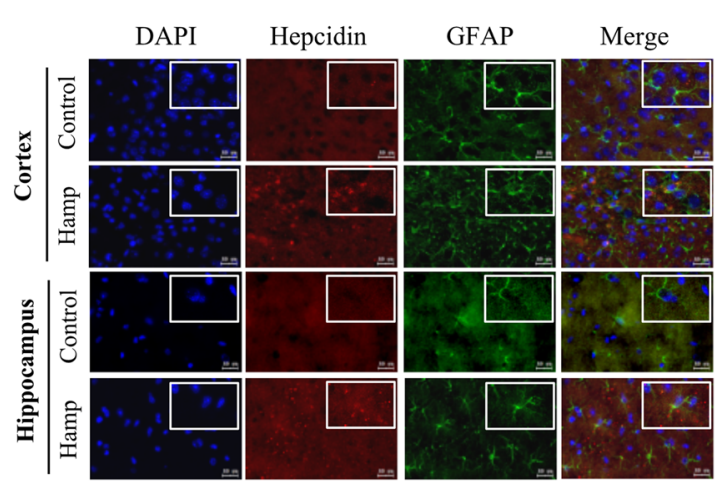

ICV injection of Hamp

ICV injection of (or vector) plasmid $\quad A \beta_{25-35}$ or saline

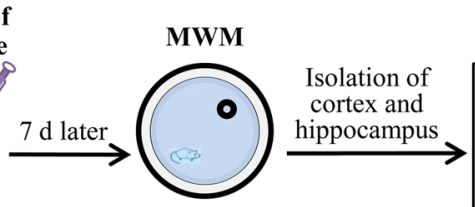

WB, qRT-PCR, IHC, IF, $\mu$-XRF, ROS, Isolation of BMVECs, etc.

d

e

f

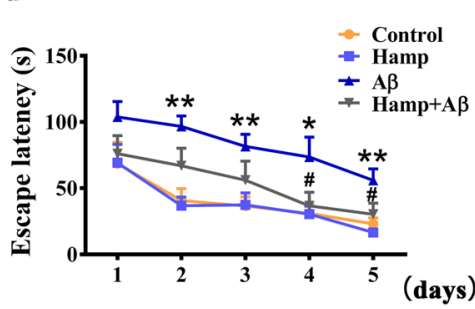

$\mathbf{g}$

Cortex

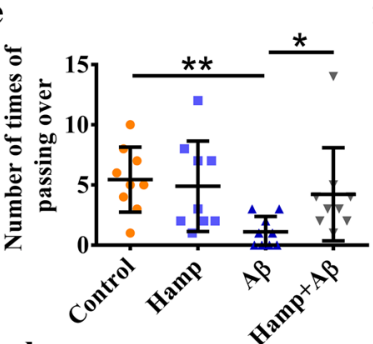

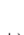

h
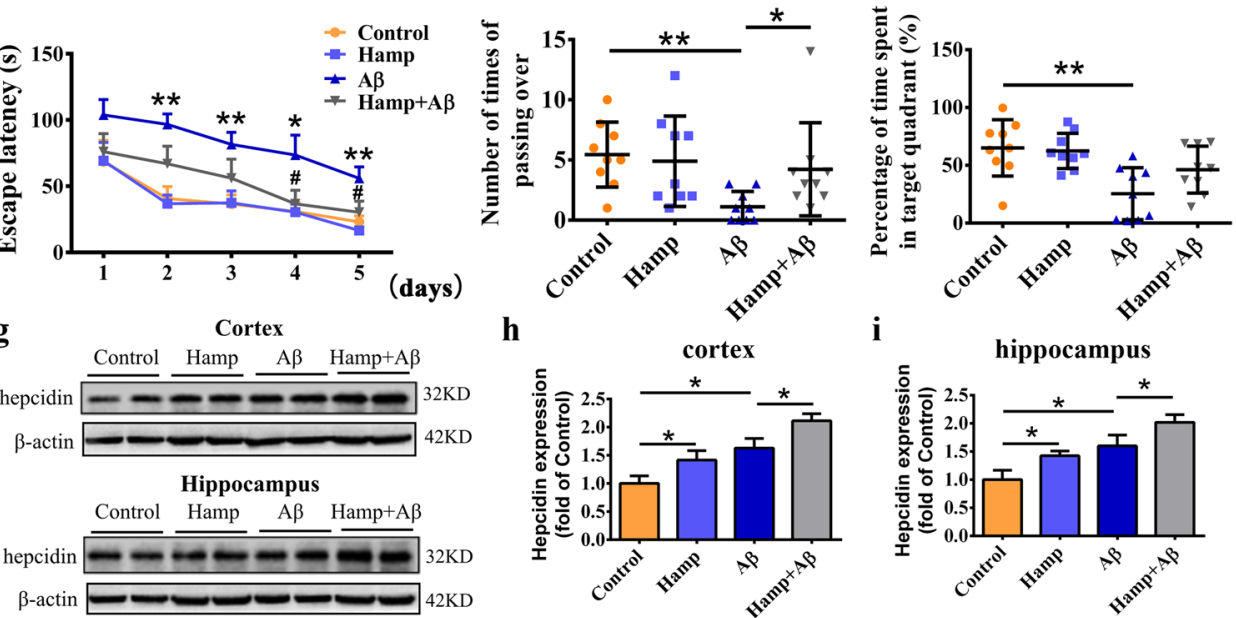

Fig. 1 Astrocyte-specific overexpression of hepcidin protected against A $\boldsymbol{\beta}$-induced cognitive decline in mice. a Quantifications of hepcidin mRNA in the cortex and hippocampus of mouse brains by qRT-PCR after 9 days of intracerebroventricular (ICV) injection. Data are presented as the means $\pm S D, n=6 .{ }^{*} P<0.01$ vs. the vector-injected control mice (Control). $\mathbf{b}$ Hepcidin (red) and GFAP (astrocyte marker, green) immunofluorescence staining were performed in the cortex and hippocampus near the lateral ventricle. DAPI (blue) was used for nuclear staining. Bar $=50 \mu \mathrm{m}$. c Experimental scheme: mice were ICV-injected with Hamp plasmid or vector control, and 2 days later injected with A $\beta_{25-35}$ or saline. The behavior performance was assessed by MWM after 7 days, and then the cortical and hippocampal tissues were excised and analyzed by various methods, as indicated. $\mathbf{d}$ Data show the changes in latency time to find the hidden platform over the 5 consecutive days of training in MWM test. Data are presented as the means $\pm \mathrm{SEM}, n=9$. ${ }^{*} P<0.05$ and ${ }^{*} P<0.01$ vs. the control group; ${ }^{*} P<0.05$ vs. the A $\beta$-treated group. $\mathbf{e}, \mathbf{f}$ The number of times the mouse traversed the platform $(\mathbf{e})$ and the percentage of time spent in the target quadrant (f) on the 6th day after removing the platform. Data are presented as the means $\pm S D, n=9$. ${ }^{*} P<0.05$ and ${ }^{*} P<0.01$. $\mathbf{g}$ Representative western blots images for detection of the hepcidin expression in the cortex and hippocampus of different mice. $\mathbf{h}$, $\mathbf{i}$ The relative expression level of hepcidin in the cortex (h) and hippocampus (i) were calculated after normalizing each specific band to its respective $\beta$-actin band, and are presented as means \pm SEM, $n=6 .{ }^{*} P<0.05$.

of Bcl-2 (anti-apoptotic protein) and Bax (pro-apoptotic protein) in the cortical and hippocampal tissues were also quantified to reflect the apoptosis status of different groups ${ }^{38}$. As shown in Fig. 2d, e, a dramatic Bcl-2 inhibition and Bax activation were observed in the cortex and hippocampus of $A \beta$-treated mice compared with the control mice, resulting in significantly reduced
Bcl-2/Bax ratios. In contrast, the Hamp $+\mathrm{A} \beta$ mice with hepcidin overexpression in astrocytes maintained the levels of both Bcl-2 and Bax, showing a relatively small change in Bcl-2/Bax ratios (Fig. 2d, e). These indicate that the elevated astrocyte hepcidin can partially alleviate $A \beta_{25-35}$-induced apoptosis in the cortex and hippocampus of the mouse brain. 

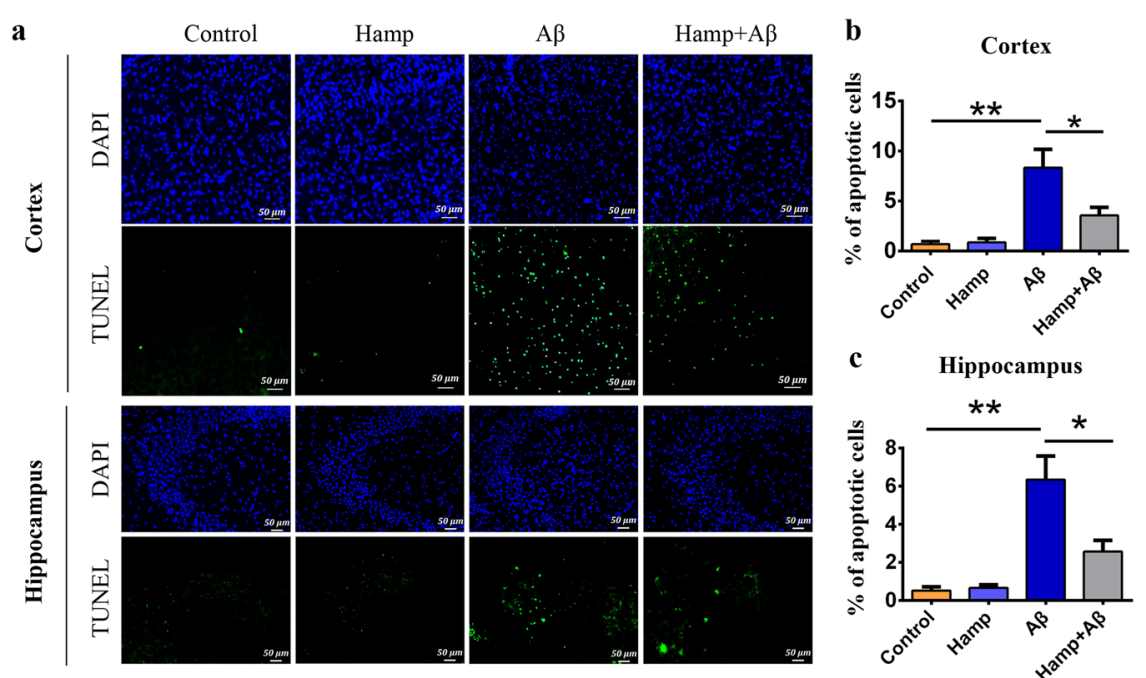

d

Cortex
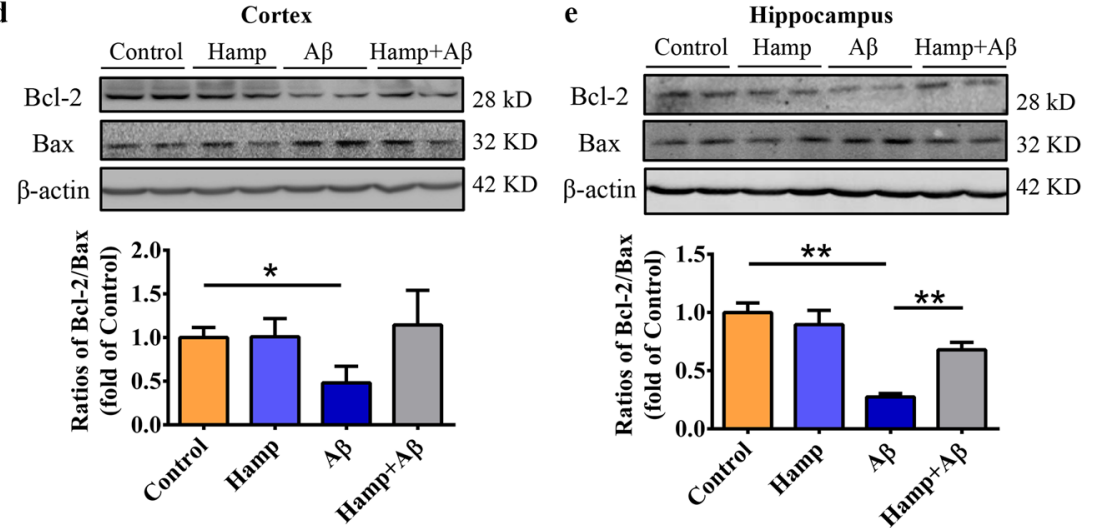

Fig. 2 Astrocyte-overexpressed hepcidin alleviated $\mathbf{A} \boldsymbol{\beta}$-induced apoptosis in the mouse brain. a TUNEL-positive cells (green) and DAPI-stained nuclei in the cortex near lateral ventricles and hippocampal CA3 regions of mice in different groups were observed. Bar $=50 \mu \mathrm{m}$. $\mathbf{b}, \mathbf{c}$ The statistical analysis of relative apoptotic cell levels in cortical sections (b) and hippocampal sections (c). Data are presented as the means \pm SEM, $n=6$. d, e Western blot was used to detect expression levels of $\mathrm{BCl}-2$ and Bax in the cortex (d) and hippocampus (e) in different groups of mice, and the ratios of $\mathrm{BCl}-2 / \mathrm{Bax}$ were calculated and expressed as fold of control. Data are presented as the means $\pm \mathrm{SEM}, n=6$. ${ }^{*} P<0.05$ and ${ }^{* *} P<0.01$.

\section{Astrocyte hepcidin overexpression reduced $A \beta$-induced oxidative damage}

Since apoptosis is usually associated with oxidative stress, we examined the levels of ROS and 4-HNE, a byproduct of lipid peroxidation during oxidative stress ${ }^{8}$. As shown in Fig. 3a, ROS generation in the cortex of A $\beta$-treated mice had a substantial increment, whereas it decreased significantly in Hamp $+\mathrm{A} \beta$ mice. Similarly, ROS level in the hippocampus of Hamp $+\mathrm{A} \beta$ mice was also lower than that of $A \beta$-treated mice (Fig. 3b). The level of 4-HNE increased largely in $A \beta_{25-35}$-injected mice compared with controls, but it reduced significantly in both the cortex and hippocampus of Hamp $+\mathrm{A} \beta$ mice (Fig. 3c, d). These demonstrate that the astrocyteoverexpressed hepcidin indeed reduces oxidative stress induced by $\mathrm{A} \beta$.

It is well known that the MAPK pathway participates in the signaling cascade of cellular stress responses ${ }^{39}$, and is closely related to the pathogenesis of $\mathrm{AD}^{40}$. This signaling pathway is further capable of modulating mitochondriamediated apoptosis in the Bcl-2 family ${ }^{41,42}$. Therefore, we explored the activation of the MAPK/ERK/p38 pathway in mice of different groups. As shown in Supplementary Fig. S3, the phosphorylation of both p38 and ERK was largely increased in the cortex and hippocampus of $A \beta_{25-35-}$ treated mice, but much less in Hamp $+\mathrm{A} \beta$ mice.

\section{Astrocyte hepcidin overexpression prevented $A \beta$-induced brain iron overload}

It is notable that excess free iron contributes to the generation of ROS and oxidative stress ${ }^{4,43}$. We, therefore, investigated whether $A \beta_{25-35}$ induces elevation of brain iron and whether the overexpression of hepcidin in astrocytes prevents iron overload and subsequently reduced oxidative stress and apoptosis. To examine iron levels, we utilized $\mu$-XRF to directly visualize iron 

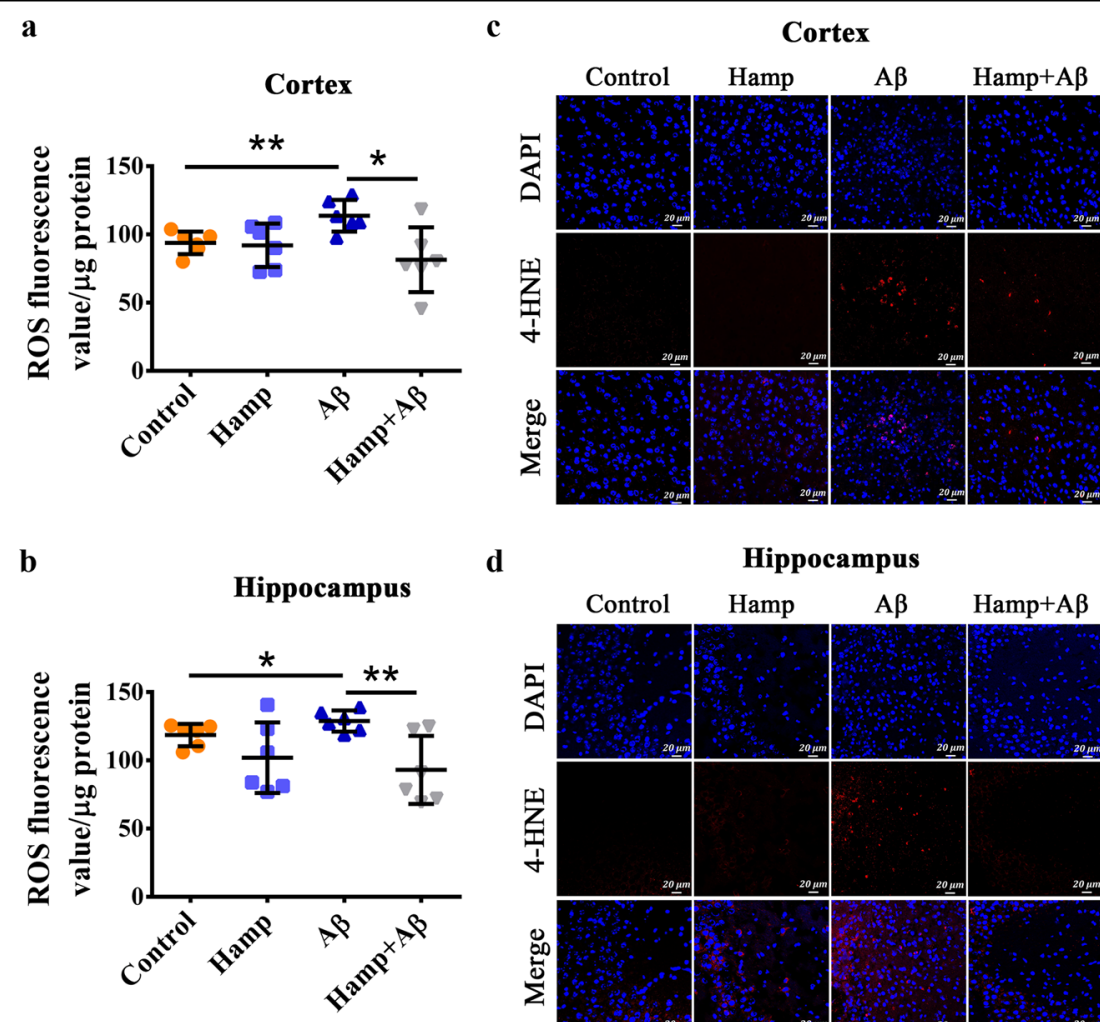

d

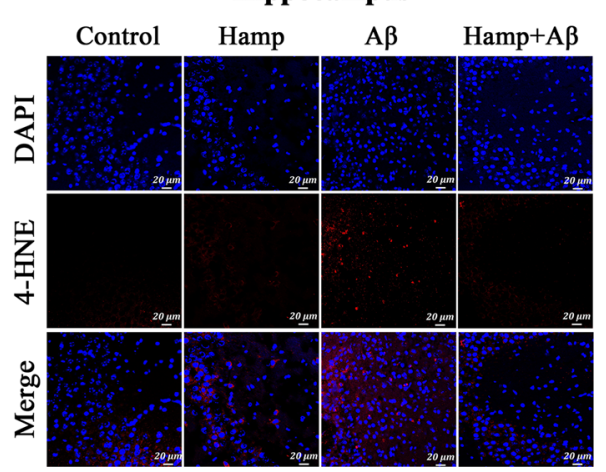

Fig. 3 Astrocyte hepcidin reduced oxidative damage. a, b Reactive oxygen species (ROS) levels of the cortex (a) and hippocampus (b) were assayed as described in the "Materials and methods". Data are presented as the means \pm SD. $n=6$. ${ }^{*} P<0.05$ and ${ }^{* *} P<0.01$. c, d Immunofluorescence staining of 4-HNE (red) was carried out in sections of the cortex (c) and hippocampus (d). DAPI was used for nuclear staining. Bar $=20 \mu \mathrm{m}$.

distribution in the cortex and hippocampus of mice in different groups. Compared with the control group, the iron content in the cortex and hippocampus of $A \beta$-treated mice increased dramatically (Fig. $4 \mathrm{a}, \mathrm{b}$ ), whereas the iron content of Hamp $+A \beta$ mice indeed reduced as compared to the $A \beta$-treated mice, although still higher than that of the control group (Fig. 4a, b). To further confirm the changes of iron level, we measured the expression of iron storage protein, L-ferritin. Consistent with the change of iron, the expression of L-ferritin in the cortex of the $A \beta$-treated mice was upregulated compared with the control mice, while that of the Hamp $+\mathrm{A} \beta$ mice decreased substantially compared with $A \beta$-treated mice (Fig. 4c). In the hippocampus, L-ferritin showed an elevation in $A \beta$ mice compared with the control mice and a reduction in Hamp $+A \beta$ mice compared with $A \beta$ mice (Fig. 4d). However, their differences did not reach statistical significance due to the wide variation of the values in the $A \beta$ group.

We have also detected whether the alterations of brain iron affected the iron in neurons by double staining of $\mathrm{H}$ ferritin with neuronal marker NeuN. As shown in Supplementary Fig. S4, the iron in the granular neurons of the hippocampus in $A \beta$-treated mice was substantially increased, whereas that of the Hamp $+A \beta$ mice was reduced compared with $A \beta$ mice, indicating the overexpression of hepcidin attenuated iron deposition in granular neurons of hippocampal CA3 regions. No significant difference in the iron levels of cortical neurons was observed between different groups of mice (Supplementary Fig. S4).

\section{Astrocyte hepcidin overexpression ameliorated $A \beta$-induced dysregulation of iron homeostasis}

To assess the effects of astrocyte-overexpressed hepcidin on $A \beta$-induced dysregulation of brain iron metabolism, we determined the expressions of iron transporters, including iron efflux protein FPN1, uptake protein transferrin receptor 1 (TfR1), and divalent metal-ion transporter 1 (DMT1) with the iron-responsive element $(+\mathrm{IRE})^{44,45}$. In the cortex, $A \beta_{25-35}$ treatment caused a significant elevation in FPN1 expression in the $A \beta$ group, and astrocyte hepcidin overexpression decreased FPN1 significantly in both the Hamp group and the Hamp $+A \beta$ group (Fig. 5a, b). TfR1 decreased significantly in $A \beta$-treated mice, but was not affected much in Hamp $+A \beta$ group compared with the control group (Fig. 5a, c). DMT1 (+IRE) did not show any statistically 


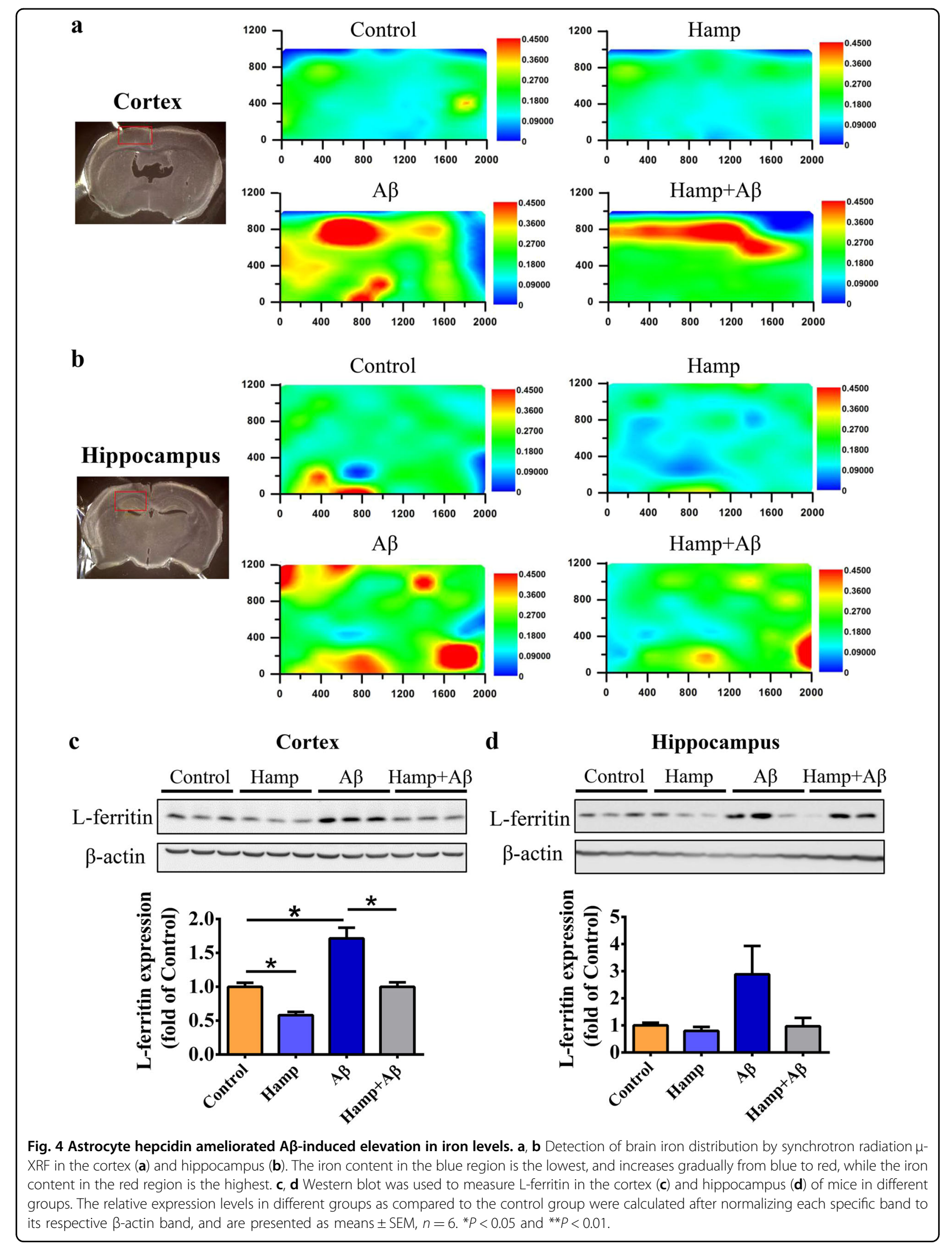




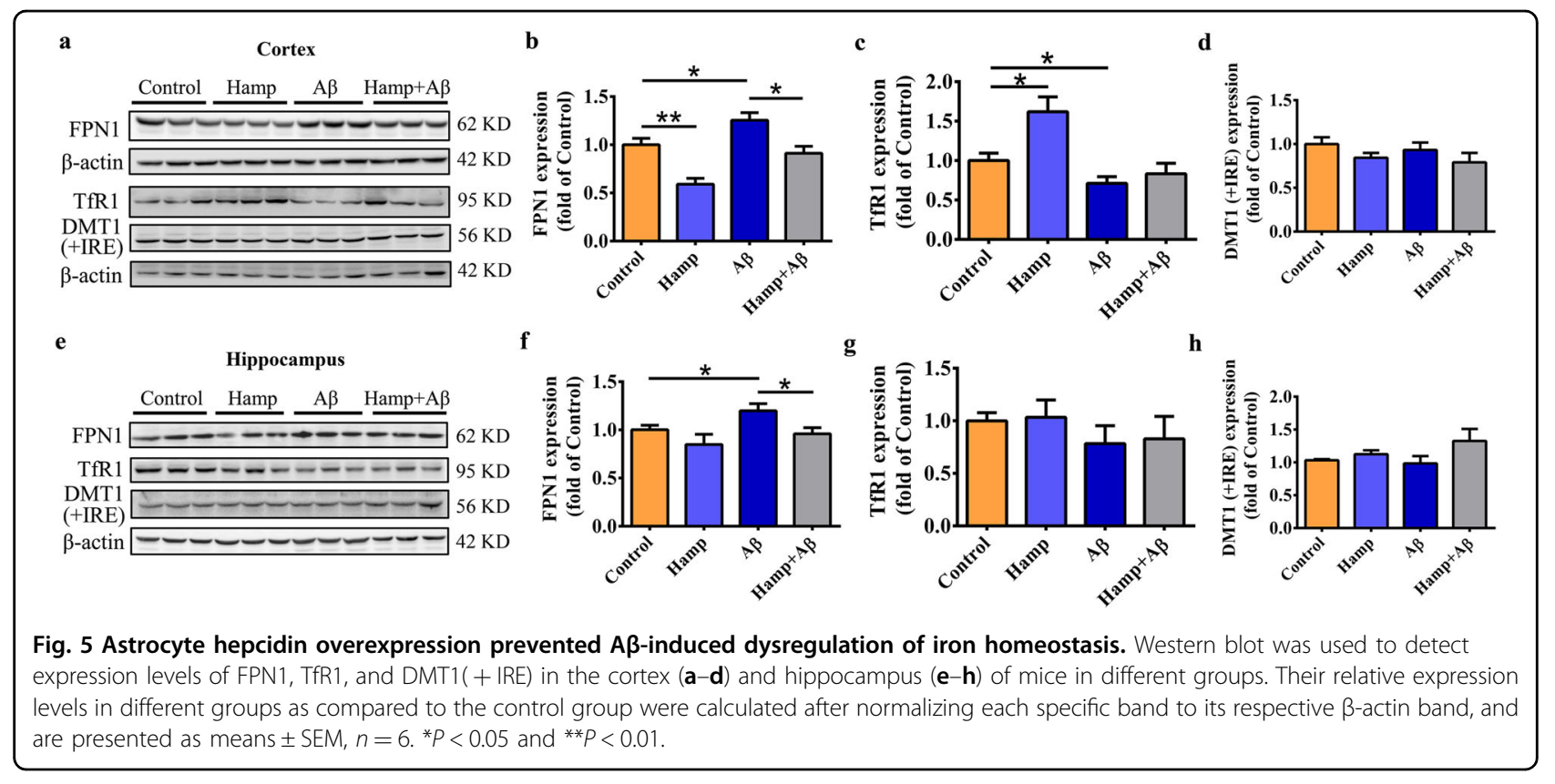

significant difference in all groups (Fig. 5a, d). In the hippocampus, the FPN1 expression in the $\mathrm{A} \beta$ group also showed an increase compared with the control group, and the Hamp $+A \beta$ group showed a decrease in FPN1 expression compared with the $A \beta$ group (Fig. $5 e, f$ ). The TfR1 and DMT1 (+IRE) expressions in the hippocampus of different groups of mice were not significantly changed (Fig. 5e, g, h). These observations indicated that $A \beta$ stimulation led to alterations of cortical and hippocampal iron homeostasis, while hepcidin overexpression in astrocytes partly ameliorated its dysregulation.

\section{Astrocyte hepcidin-regulated iron influx at BBB}

As indicated, hepcidin from astrocyte could interact with FPN1 on BMVECs ${ }^{31,32}$, which may influence the iron influx at $\mathrm{BBB}$. We therefore explored whether the decrease in brain iron in Hamp $+\mathrm{A} \beta$ mice was achieved by inducing degradation of FPN1 on BMVECs. The BMVECs were isolated from brain tissues of mice of different groups, and their protein expression levels were determined by western blot. When treated with $\mathrm{A} \beta_{25-35}$, the levels of FPN1 and TfR1 were upregulated, indicating a higher iron release from blood to brain tissue (Fig. $6 \mathrm{a}-\mathrm{d})$. In contrast, the expression of FPN1 on BMVECs was decreased significantly in the Hamp group (Fig. 6a, b). The decrease of FPN1 reduced iron release from BMVECs and resulted in higher iron content in BMVECs, which was consistent with the upregulation of iron storage protein L-ferritin and $\mathrm{H}$-ferritin (Fig. 6c, d). Therefore, in the Hamp $+\mathrm{A} \beta$ group, FPN1 significantly reduced as compared with the A $\beta$-treated group (Fig. 6a, b), reflecting a lower iron efflux from BMVECs into the brain tissue. These results imply that hepcidin overexpression in astrocytes could reduce brain iron uptake by inducing degradation of FPN1 on BMVECs, thereby attenuating iron deposition resulted from $A \beta_{25-35}$ treatment.

\section{Astrocyte hepcidin attenuated $A \beta$-induced inflammation as well}

It has been reported that $A \beta$ can activate the microglia and increase the release of inflammatory factors, and hepcidin can prevent acute cytokine-induced inflammatory responses ${ }^{46,47}$. Therefore, we determined the levels of microglia and inflammatory factors in different groups of mice. The Iba1 immunohistological staining in the cortex and hippocampus revealed substantial changes in the number and morphology of microglia in mice injected with $A \beta_{25-35}$ compared with the control group (Fig. 7a-c), whereas the Hamp $+A \beta$ mice showed a decreased number of microglia compared with $A \beta$-injected mice (Fig. $7 \mathrm{a}-\mathrm{c})$. These inferred that hepcidin could suppress A $\beta$-induced microglial activation. Consistent with this, the inflammatory cytokines, tumor necrosis factor $\alpha$ (TNF- $\alpha$ ) and interleukin $1 \beta$ (IL-1 $\beta)$, were upregulated in the cortex of $A \beta$-injected mice compared with the control mice (Fig. $7 d$, e), whereas those of the Hamp $+A \beta$ mice remained steady. On the other hand, the suppressor of cytokine signaling 3 (SOCS-3) was largely reduced in the $A \beta$-injected mice, but its level in Hamp $+A \beta$ mice did not decrease significantly compared with the control mice (Fig. 7f). These indicated that astrocyte hepcidin effectively suppressed $A \beta$-induced inflammation. 

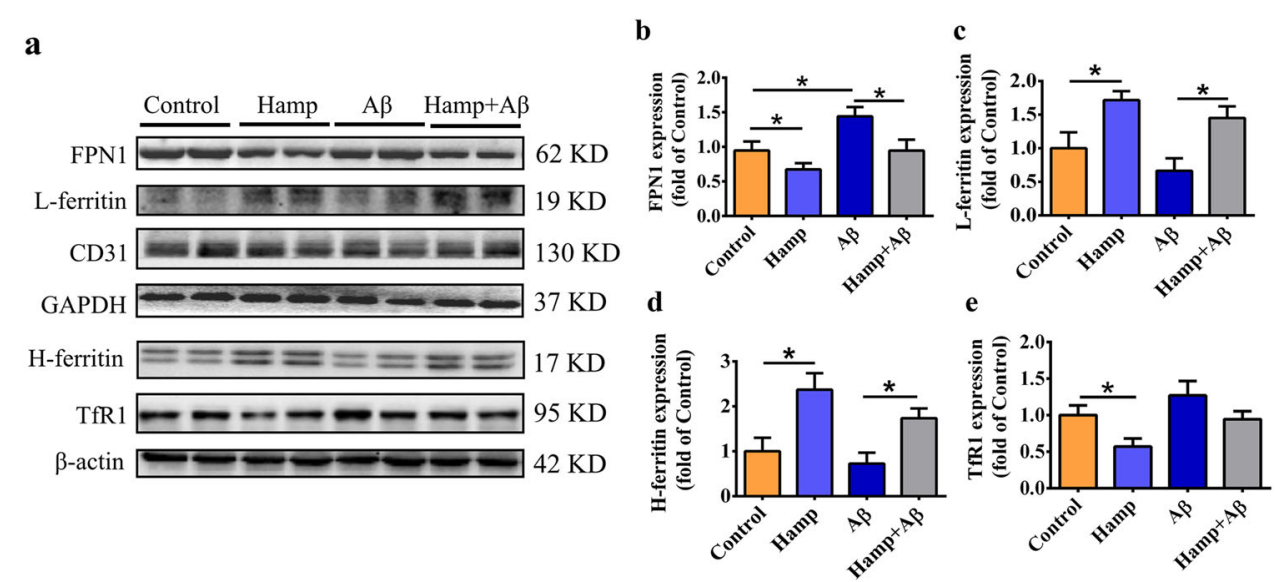

Fig. 6 Astrocyte hepcidin overexpression reduced the iron influx from brain microvascular endothelial cells (BMVECs). BMVECs were isolated from cortical and hippocampal tissues. Western blot was used to detect expression levels of FPN1 (a, b), L-ferritin (a, $\mathbf{c})$, H-ferritin (a, d), and TfR1 (a, e). CD31 was used as a specific marker for blood vessels, and GAPDH and $\beta$-actin were internal controls. The relative expression levels of FPN1 and L-ferritin in different groups as compared to the control group were calculated after normalizing each specific band to the CD31 band, the relative levels of $\mathrm{H}$-ferritin and TfR1 were calculated after normalizing each specific band to their respective $\beta$-actin band. Data are presented as means \pm SEM,$n=6$. ${ }^{*} P<0.05$ and ${ }^{*} P<0.01$.

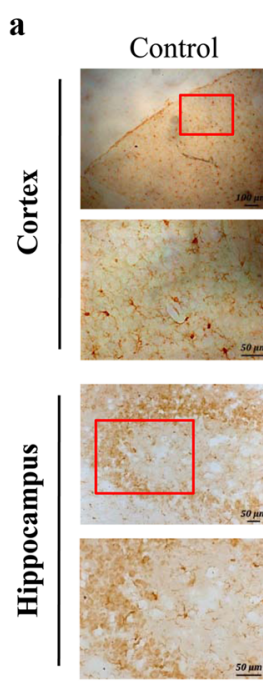

d

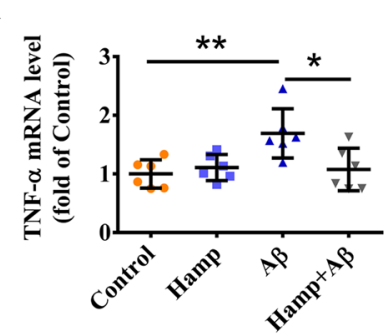

Hamp
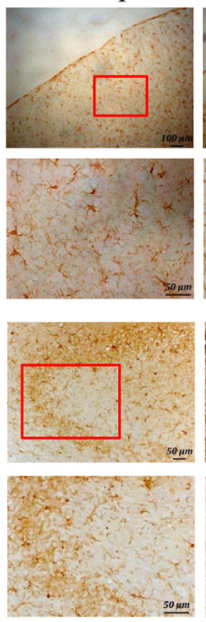

$\mathrm{A} \beta$
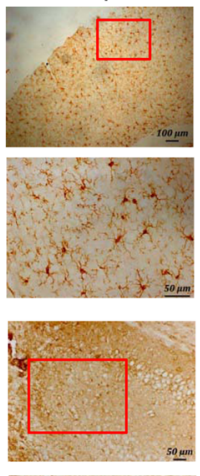

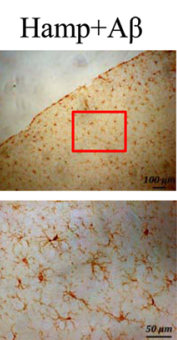

b
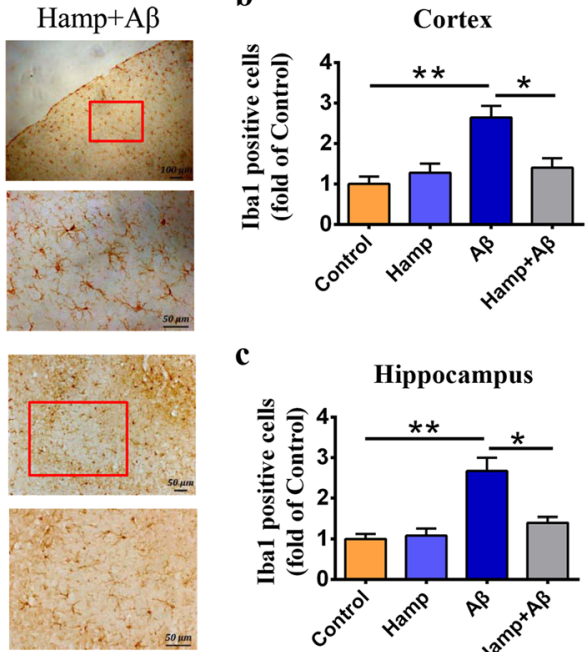

e

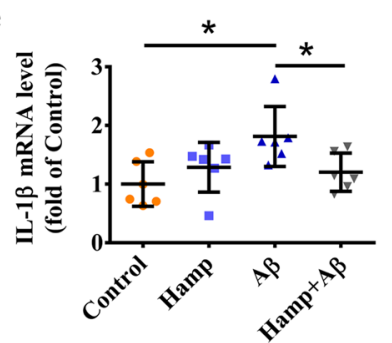

c

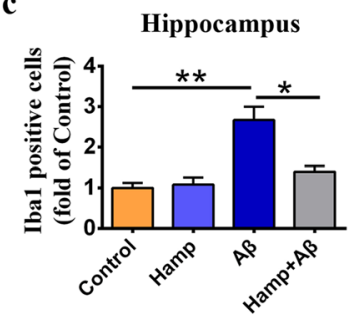

f

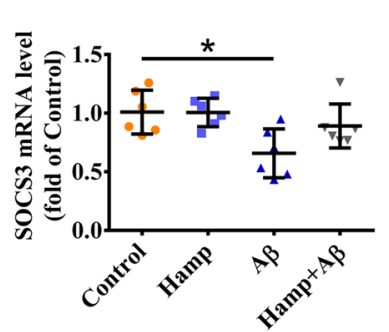

Fig. 7 Astrocyte hepcidin attenuated $\mathbf{A} \boldsymbol{\beta}$-induced inflammation. a Immunohistochemical stainings of the microglia marker-lba1 in the cortex and hippocampus were performed. Bar $=100 \mu \mathrm{m}$ or $50 \mu \mathrm{m}$, as indicated. $\mathbf{b}, \mathbf{c}$ The statistical analysis of relative Iba1-positive cell levels in cortical sections (b) and hippocampal sections (c). Data are presented as the means \pm SEM, $n=6$. $\mathbf{d}-\mathbf{f}$ Detection of TNF-a (d), IL-1 $\beta$ (e), and SOCS-3 (f) mRNA levels in mouse cortex by qRT-PCR. Data are presented as the means $\pm S D, n=6$. ${ }^{*} P<0.05$ and ${ }^{* *} P<0.01$. 


\section{Discussion}

It has been reported that increasing hepcidin expression or treatment with hepcidin peptide could reduce brain iron and protect neurons from iron-mediated oxidative damage $^{26,27}$, and the expression and distribution of hepcidin in the brain were closely depended on age and inflammatory status ${ }^{28-30}$. Besides, hepcidin secreted by astrocytes was proposed to control iron intake at BBB by regulating FPN1 on BMVECs ${ }^{31,32}$. These imply that modulating the level of hepcidin in the brain, especially hepcidin expressed by astrocytes, might be a promising therapy opportunity for iron-overload brain disorder, including $\mathrm{AD}$. In this study, in vivo evidences were collected to show whether increasing the expression of astrocyte hepcidin could reduce brain iron level and subsequently relieve $\mathrm{AD}$ symptoms.

We successfully overexpressed hepcidin in astrocytes of mice using a modified pAAV plasmid with astrocytespecific GFAP promoter and then injected mice with $\mathrm{A} \beta_{25-35}$ to induce injury. Behavioral experiments revealed that the elevated astrocyte hepcidin partially protected spatial learning and memory impairment in mice induced by neurotoxic $A \beta_{25-35}$, which possibly involved its protection on synaptic function because the PSD-95 expression was not reduced significantly in Hamp $+A \beta$ mice. From the stained tissue sections of the cortex and hippocampus, largely decreased numbers of apoptotic cells were observed in astrocyte hepcidin overexpressing mice. The levels of ROS and 4-HNE were also reduced. By assessing iron metabolism, we found that astrocyte hepcidin overexpression indeed decreased $A \beta$-induced brain iron overload. Besides, the $A \beta$-induced iron dyshomeostasis, reflected by the alterations of various iron transporters, was also alleviated by the overexpressed astrocyte hepcidin. These all implied that the overexpression of hepcidin in astrocytes protected mice from $A \beta$-induced cognitive decline, cell apoptosis, and oxidative damage in the brain, which possibly linked to its regulation of brain iron accumulation.

The assessment of the FPN1 level on BMVECs showed that FPN1 expression was significantly decreased by the elevated astrocyte hepcidin. Consistent with this, Lferritin in BMVECs of Hamp $+\mathrm{A} \beta$ mice markedly increased, reflecting an intracellular iron accumulation status of BMVECs. Due to the activation of the cellular iron regulatory systems that initiated by the interaction of iron regulatory proteins (IRPs) with IREs in responses to a higher iron load ${ }^{13,48}$, ferritin expression would increase, but TfR1 should decrease in the Hamp $+A \beta$ mice to lower the iron intake. However, no statistically significant decrease in TfR1 was observed, which likely due to the wide variation of the values in Hamp $+\mathrm{A} \beta$ group. These results inferred that the overexpressed astrocyte hepcidin influenced iron uptake at $\mathrm{BBB}$ and decreased brain iron load, thereby protecting against $A \beta$-induced injury.

Previous studies by Urrutia et al. have found that hepcidin peptide could attenuate $\mathrm{A} \beta$-induced inflammatory and pro-oxidative responses in astrocytes and microglia, alleviating oxidative damage and neurotoxicity ${ }^{47}$. However, the involvement of hepcidin's regulation of iron metabolism in these inhibitory effects was not investigated. Our results showed that overexpression of astrocyte hepcidin in mice could also inhibit $A \beta$-induced microglial activation and block inflammatory cytokine release. This protective effect could be primarily attributed to the function of hepcidin in reducing brain iron load, and could also be partially due to its inhibition on cytokines TNF- $\alpha$ and IL- $1 \beta$ and its activation on SOCS $-3^{46,49}$.

As realized of the limitation on drug diffusion range of ICV injection, we additionally performed hippocampal injections of hepcidin and $A \beta_{25-35}$, to fully evaluate the protective effects of hepcidin. As shown in Supplementary Fig. S5, the hippocampal injection of $A \beta_{25-35}$ led to severe apoptosis in the dentate gyrus of the hippocampus, and also induced the increase of 4-HNE-positive cells and microglia. When hepcidin was overexpressed in astrocytes, these cell damage and inflammatory responses caused by $A \beta_{25-35}$ were remarkably alleviated. These results were consistent with the result of ICV injection, which further confirmed the protective effects of astrocyte hepcidin on hippocampal damage.

It was noted that the role of hepcidin in neuronal iron load demonstrated by different studies were contradictory. In contrast to the beneficial effects revealed by Urrutia and Zhou et al. ${ }^{26,27,47}$, researchers found that a high level of hepcidin could be destructive ${ }^{25,50}$. The increased hepcidin produced by astrocytes and microglia directly acted on FPN1 of neurons, leading to a reduction in iron export from neurons, which aggravated neuronal oxidative damage ${ }^{29,51,52}$. Recently, Vela proposed a dual role of hepcidin in the brain, suggesting whether there is inflammation or not is the main reason for this contradiction $^{25}$. He hypothesized that pretreatment with hepcidin could protect brain cells from oxidative damage, while hepcidin induction during inflammation would increase iron-dependent injury ${ }^{25}$. In our study, the overexpression of hepcidin in astrocyte was a pretreatment factor, and a protective effect did occur. Whether the beneficial role of astrocyte hepcidin can sustain with increasing levels of inflammation requires more in-depth research.

In summary, as shown in Fig. 8, we proposed that the hepcidin overexpressed by astrocytes primarily reduced FPN1 of BMVECs, thereby reduced iron efflux from BMVECs and lowered brain iron content. The high level 


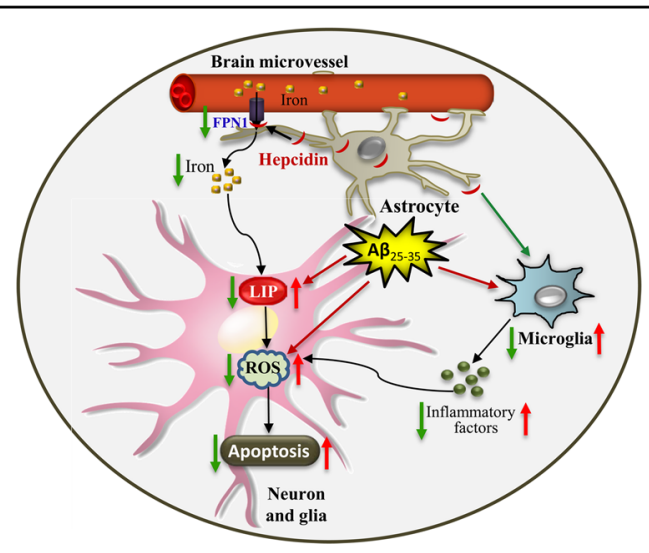

Fig. $8 \mathrm{~A}$ schematic representation of the protective role of astrocyte hepcidin on $\mathbf{A} \boldsymbol{\beta}$-induced apoptosis. $A \beta$ treatment results in higher intracellular LIP, which can induce oxidative stress and inflammation, leading to neuronal death. When hepcidin secreted by astrocytes is upregulated, it interacts with FPN1 on brain microvascular endothelial cells (BMVECs) and reduces brain iron intake, thereby ameliorating LIP elevation caused by A $\beta$. This in turn attenuates irondependent reactive oxygen species (ROS) production. Besides, the overexpressed hepcidin also inhibits the activation of microglia induced by $A \beta$, and blocks the release of pro-inflammatory factors. Ultimately the apoptosis induced by $A \beta$ is largely prevented.

of the cellular liable iron pool (LIP) caused by $A \beta$ was then ameliorated ${ }^{53}$. This in turn attenuated irondependent oxidative damage, and ultimately suppressed the apoptosis induced by A $\beta$ via MAPK signals in neurons and glial cells of the cortex and hippocampus. Besides, the overexpressed hepcidin also inhibited the $A \beta$-induced activation of microglia, blocked the release of proinflammatory factors, and induced the increase of cytokine suppressors. These effectively prevented the aggravation of apoptosis and improved the behavioral performance of mice. Our study, for the first time, demonstrated with in vivo evidence that astrocyte-specific overexpression of hepcidin altered brain iron metabolism, and protected against $A \beta$-induced oxidative damage in mice, which provides more insights into the therapy of iron overloaded-related brain disorders.

\section{Materials and methods \\ Animals}

Three-month-old male Balb/C mice were obtained from Hebei Medical University. Mice were housed under conditions controlled for temperature $\left(22^{\circ} \mathrm{C}\right)$ and humidity (40\%), using a $12 \mathrm{~h} / 12 \mathrm{~h}$ light/dark cycle. Mice were fed a standard rodent diet and water ad libitum. All procedures were carried out in accordance with the National Institutes of Health Guide for the Care and Use of Laboratory Animals, and were approved by the Animal Ethics Committee of Hebei Normal University.

\section{Plasmid construction}

To clone the astrocyte-specific expression plasmid of hepcidin (Hamp), pAAV-EGFP plasmid was used as a vector backbone. The promoter sequence of the glial fibrillary acidic protein (GFAP) was amplified by PCR $^{54}$, and inserted into the pAAV-EGFP plasmid to replace its CMV promoter. The full-length cds of the mouse Hamp gene were amplified and inserted into the MCS and replaced the EGFP gene. The $\beta$-globin intron was also removed. This expression vector was named as pAAVgfap:Hamp. The pAAV-gfap backbone vector without inserting Hamp was used as control. The primers used to amplify GFAP promoter and Hamp gene were as follows:

GFAP promoter forward: 5'-CCGACGCGTGAGCTC CCACCTCCCTCTCTG- ${ }^{\prime}$

GFAP promoter reverse: $5^{\prime}$-CCGGAATTCTCACCT GCTCTGGCTCTGCTCGCT- $3^{\prime}$

Hamp forward: 5'-CCGGAATTCATGGCACTCA GCACTCGGACC- $3^{\prime}$

Hamp reverse: 5'-CCGCTCGAGCTATGTTTTGCA ACAGATACCACACTG- $3^{\prime}$.

\section{Antibodies}

The following antibodies were used: $\beta$-actin antibody (cw0096m, CWbio, China), FPN1 antibody (MTP11-S, ADI, USA), DMT1 (+IRE) antibody (NRAMP21-S, ADI, USA), 4-HNE antibody (HNE-11S, ADI, USA), TfR1 antibody (ab84036, Abcam, USA), L-ferritin antibody (ab109373, Abcam, USA), H-ferritin antibody (ab183781, Abcam, USA), hepcidin antibody (ab30760, Abcam, USA), A $\beta_{22-35}$ antibody (A3356, Sigma, USA), phospho-p38 (pp38) antibody (4511S, CST, USA), p38 antibody (8690S, CST, USA), phospho-ERK (p-ERK) antibody (9102S, CST, USA), ERK antibody (4372S, CST, USA), Bcl-2 antibody (12789-1-AP, Proteintech, China), Bax antibody (50599-2Ig, Proteintech, China), GFAP antibody (MAB360, Millipore, USA), Iba1 antibody (MABN92, Millipore, USA), NeuN (ab104224, Abcam, USA), CD31 (77699T, CST, USA), PSD-95 (ab18258, Abcam, USA), anti-rabbit IgG (RPN4301, Amersham, UK), anti-mouse IgG (RPN4201, Amersham, UK), DyLight 488 goat anti-mouse IgG (A23210, Abbkine, USA), DyLight 549 goat anti-rabbit IgG (A23320, Abbkine, USA), and DyLight 549 goat antimouse IgG (A23310, Abbkine, USA).

\section{Plasmid injection, electroporation, and $A \beta$ treatment}

Mice, weighing $22-25 \mathrm{~g}$, were randomly divided into four groups, nine mice per group for behavior tests or six mice per group for the rest of other assays according to the previous experiments ${ }^{36}$. Two groups were injected with pAAV-gfap:Hamp $(1.5 \mu \mathrm{g} / \mu \mathrm{l}, 4 \mu \mathrm{l})$ via ICV injection into the right lateral ventricle $(0.5 \mathrm{~mm}$ posterior and $1.0 \mathrm{~mm}$ lateral to the bregma, $2.5 \mathrm{~mm}$ below the surface of skull) or intrahippocampal injection into the right 
hippocampus as specifically stated $(1.9 \mathrm{~mm}$ posterior and $1.0 \mathrm{~mm}$ lateral to the bregma, $1.5 \mathrm{~mm}$ below the surface of skull). The other two groups were injected with vector plasmid control. Following injection, the brains were electroporated with square wave pulses from an Electro Square Porator ECM830 (BTX Inc, San Diego, CA). The tweezer-like electrodes, 6-8 $\mathrm{mm}$ apart, were placed on the mouse skull across the injection site, with a positive electrode on the right side of the mouse skull such that the DNA was driven into the cells on right side of the brain. The brains were pulsed three times for $50 \mathrm{~ms}$ each at $125 \mathrm{~V}$ at $1 \mathrm{~s}$ intervals.

$\mathrm{A} \beta_{25-35}$ peptide (A4559, Sigma, USA) or $\mathrm{A} \beta_{35-25}$ peptide (A2201, Sigma, USA) was dissolved in sterile saline and aggregated by incubation at $37^{\circ} \mathrm{C}$ for 4 days before use as previously described ${ }^{36}$. After $48 \mathrm{~h}$ of Hamp plasmid injection, the aggregated form of $A \beta_{25-35}$ was administrated $(7.5 \mathrm{nmol}$ in $5 \mu \mathrm{l}$ saline) into one of the Hamp plasmids injected group and one of the control group. The rest two groups were injected with saline as controls. The four groups were named as control (vector plasmid + saline), Hamp (Hamp plasmid + saline), $\mathrm{A} \beta$ (vector + $\mathrm{A} \beta_{25-35}$ ), and Hamp $+\mathrm{A} \beta$ (Hamp plasmid $+\mathrm{A} \beta_{25-35}$ ). After injection, mice were housed for 7 days under normal conditions. Mice were trained and tested in a Morris water maze (MWM), and then killed under anesthesia by transcardiac perfusion. The brains were immediately collected and subjected to further analyses, including tissue section, western blot, etc. All the experiments were repeated at least three times. Blinding was not performed in the analysis.

\section{Behavioral test by MWM}

Spatial learning and memory deficits were assessed using the MWM test ${ }^{36}$. A visible round platform (diameter $=9 \mathrm{~cm}$ ) was placed in the water maze tank during the training period. For the hidden platform test, the platform was placed $1 \mathrm{~cm}$ below the water surface at the midpoint of the fourth quadrant. All mice were performed with four trials per day for 5 days, with the escape platform kept at a constant position. Each trial lasted for $120 \mathrm{~s}$ or ended as soon as the mice reached the submerged platform. The "escape latency", the time to reach the platform in the water maze, was recorded. At the 6th day, a probe test was performed after removing the platform, using the metric "time spent in the target quadrant" to investigate the maintenance of memory.

\section{Quantitative real-time reverse transcription-PCR (qRT-PCR)}

The total RNA from cortical or hippocampal tissue was extracted by TRIzol agent (Invitrogen, China). Total RNA was reverse-transcribed with MMLV reverse transcriptase (TaKaRa Biotechnology, China) and Oligo-dT primers (TianGen Biotechnology, China). The SYBR green PCR
Master Mix (Beijing ComWin Biotechnology, China) was used for PCR amplification. The cycle time $(\mathrm{Ct})$ values for the gene of interest were first normalized with $\beta$-actin in the same sample, and then the relative differences between the control and each of the other groups were calculated using the equation $2^{-\Delta \Delta \mathrm{Ct}}$, and expressed as relative fold changes of the control group. The expression of hepcidin mRNA and inflammatory factors mRNA (TNF- $\alpha$, IL- $1 \beta$ and SOCS-3) were determined. The primer sequences used for amplification were as follows:

$\beta$-actin forward: $5^{\prime}$-AGGCCCAGAGCAAGAGAGG TA-3'

$\beta$-actin reverse: $5^{\prime}$-TCTCCATGTCGTCCCAGTTG-3'

Hepcidin forward: 5'-AGACATTGCGATACCAATG CA-3'

Hepcidin reverse: 5'-GCAACAGATACCACACTGG GAA-3'

TNF- $\alpha$ forward: $5^{\prime}$-AGGCGGTGCCTATGTCYCA- ${ }^{\prime}$

TNF- $\alpha$ reverse: $5^{\prime}$-GAGGCCATTTGGGAACTTCT-3'

IL-1 $\beta$ forward: 5'-GAAATGCCACCTTTTGACAGT G-3'

IL-1 $\beta$ reverse: $5^{\prime}$-CTGGATGCTCTCATCAGGACA-3'

SOCS-3 forward: 5'-GTGGAGAGGCTGAGGGACT $\mathrm{C}-3^{\prime}$

SOCS-3 reverse: 5'-GGCTGACATTCCCAGTGCTC-3'

\section{Assessment of apoptosis}

The mouse brains were postfixed with $4 \%$ paraformaldehyde in $0.1 \mathrm{M}$ phosphate buffer. Serial coronal sections were cut at $15-\mu \mathrm{m}$ thick on a freezing microtome (Leica CM1950, Leica Microsystems, China) and mounted onto slides. The presence of apoptosis in the mouse cortex and hippocampus was assessed by the terminal deoxynucleotidyl transferase-mediated FITC-12-dUTP nick-end labeling method (TUNEL) following the manufacturer's protocol (TUNEL BrightGreen Apoptosis Detection Kit, Vazyme, China). Nuclei were counterstained with DAPI. For each group, sections from three different mice were stained, and the numbers of TUNELDAPI-positive cells located at similar positions in all groups were quantified for statistical analysis.

\section{Western blot analysis}

Tissues of the cortex and hippocampus were homogenized and sonicated in RIPA buffer containing 1\% NP40 and protease inhibitor cocktail tablets (Roche Diagnostics $\mathrm{GmbH}$, Roche Applied Science, Germany). After centrifugation at $12,000 \times g$ for $20 \mathrm{~min}$ at $4{ }^{\circ} \mathrm{C}$, the supernatant was collected, and protein concentration was measured using BCA Protein Quantification Kit (Yeasen Biotechnology, China). In total, $30 \mu \mathrm{g}$ of protein from each sample was resolved by SDS-PAGE on $12 \%$ or $10 \%$ gels and then transferred to NC membranes. The membranes were blocked in $5 \%$ non-fat milk TBS-T buffer $(20 \mathrm{mM}$ 
Tris- $\mathrm{HCl}, 137 \mathrm{mM} \mathrm{NaCl}$, and $0.1 \%$ tween-20, $\mathrm{pH}$ 7.6) for $1.5 \mathrm{~h}$ at room temperature, followed by incubation with primary antibody overnight at $4{ }^{\circ} \mathrm{C}$. After washing four times with TBS-T, the membranes were then incubated with HRP-conjugated secondary antibody for $1.5 \mathrm{~h}$ at room temperature. Immunoreactive proteins were detected using the enhanced chemiluminescence method and quantified by transmittance densitometry (FUJIFILM Corporation, Tokyo, Japan).

\section{Immunohistochemistry and immunofluorescence}

For immunohistochemical staining, sections of the cortex and hippocampus were immersed in methanol with $3 \%$ hydrogen peroxide $\left(\mathrm{H}_{2} \mathrm{O}_{2}\right)$ for 20 min to reduce endogenous peroxidase activity. Antigen retrieval was performed in a microwave oven for $10 \mathrm{~min}$ in $10 \mathrm{mM}$ citrate buffer ( $\mathrm{pH}$ 6.0). After blocking for $1 \mathrm{~h}$ with normal goat serum, the slices were incubated overnight at $4{ }^{\circ} \mathrm{C}$ with mouse anti-Iba1 monoclonal antibody (1:500). The sections were then incubated with biotinylated goat antimouse serum for $1 \mathrm{~h}$ at $37^{\circ} \mathrm{C}$. Thereafter, sections were treated with avidin-biotinylated horseradish peroxidase complex (Zymed Laboratories, 1:200) for $1 \mathrm{~h}$ at $37^{\circ} \mathrm{C}$ and then stained using a $3,3^{\prime}$-diaminobenzidine tetrahydrochloride (DAB) kit (Zsbio, China). After staining, the sections were rinsed with tap water for $20 \mathrm{~min}$ to block the reaction, followed by the gradient dehydration with alcohol, and then were transparentized by xylene and sealed by resin adhesive.

For the immunofluorescence assay, after blocking for $1 \mathrm{~h}$ with goat serum, the slices were incubated overnight at $4{ }^{\circ} \mathrm{C}$ with mouse anti-GFAP monoclonal antibody (1:500), rabbit anti-hepcidin antibody (1:300), or rabbit anti-4-HNE antibody (1:400). The slices were washed three times with $0.01 \mathrm{M}$ PBS for $5 \mathrm{~min}$. Secondary antibodies DyLight 488 AffiniPure Goat Anti-Mouse IgG or DyLight 549 AffiniPure Goat Anti-Rabbit IgG were then used in incubation for $1 \mathrm{~h}$ at $37^{\circ} \mathrm{C}$. Finally, after washing and mounting, the sections were photographed. Negative controls were processed using the same procedures, but the primary antibody was omitted. All sections were visualized and quantified under either an upright fluorescence microscope (ZEISS Axio Imager, Germany) or a fluorescence confocal microscope (Olympus FV3000, Japan). For each group, quantification was performed in sections from three different mice.

\section{Measurement of ROS}

ROS levels were quantified by measuring the fluorescence of $2^{\prime}, 7^{\prime}$-dichlorofluorescein diacetate (DCFH-DA) using a commercial kit (Nanjing Institute of Bioengineering, Nanjing, China) according to the manufacturer's instructions ${ }^{55}$. First, the dissected cortical or hippocampal tissues were placed in $0.01 \mathrm{M}$ pre-cooled PBS, and then cut into pieces with medical scissors and digested with trypsin at $37^{\circ} \mathrm{C}$ for $10 \mathrm{~min}$. The formulation was then filtered using a $200-\mu \mathrm{m}$ membrane filter and centrifuged at $500 \times g$ for $10 \mathrm{~min}$. The cell pellet was resuspended and diluted with PBS to a final concentration of $5 \times 10^{6}$ cells/ $\mathrm{ml}$. The cells were incubated with $10 \mu \mathrm{M}$ DCFH-DA for $50 \mathrm{~min}$ at $37^{\circ} \mathrm{C}$ in the dark, and then centrifuged at $1000 \times g$ for $10 \mathrm{~min}$ at $4^{\circ} \mathrm{C}$. The pellet was washed twice with PBS and resuspended in PBS. Fluorescence intensity was detected by a multi-function microplate reader (Synergy H4, BioTek, VT, USA) at an optimal excitation wavelength of $485 \mathrm{~nm}$ and an emission wavelength of $525 \mathrm{~nm}$.

\section{Synchrotron radiation micro X-Ray fluorescence ( $\mu$-XRF)}

The fixed brain was subjected to gradient dehydration in 10, 20, and $30 \%$ sucrose solutions, and then frozen and sliced to a thickness of $50 \mu \mathrm{m}$, and attached to a 3-mm thick Mylar film. The brain slices were dried and placed in a vacuum desiccator. At the 4W1B line station of the Beijing Synchrotron Radiation Facility (BSRF) center, Xray fluorescence spectrometer was used to measure the distribution of iron elements in the slices. The range is from $150 \mathrm{~mA}$ to $250 \mathrm{~mA}$, and the electron energy in the storage ring is $2.2 \mathrm{GeV}$. The size of the $\mathrm{X}$-ray spot is $50 \times$ $50 \mu \mathrm{m}$. The energy of the incident $\mathrm{X}$-ray is monochromated at $15 \mathrm{keV}$ by a W/B4C high photon flux duallayer film single-frequency device, and is focused by a multi-capillary lens to a diameter of $50 \mu \mathrm{m}$. The live time at each point is $25 \mathrm{~s}$, with a step size of $100 \mu \mathrm{m}$. The scan area for the cortical region is $2000 \times 1000 \mu \mathrm{m}$, and for the hippocampal region is $2000 \times 1200 \mu \mathrm{m}$. Data conversion was performed by PyMca software and plotted with Origin 8.0.

\section{Isolation of BMVECs from mouse brain}

The anesthetized mice were perfused with pre-cooled $0.9 \%$ saline, and BMVECs from the tissues of the cerebral cortex and hippocampus were isolated as reported with small modifications ${ }^{56,57}$. The separated tissues were placed in a pre-cooled homogenizer after weighting. Precooled HBSS buffer (HEPES $10 \mathrm{mM}, \mathrm{NaCl} 141 \mathrm{mM}, \mathrm{KCl}$ $4 \mathrm{mM}, \mathrm{MgSO}_{4} \cdot 3 \mathrm{H}_{2} \mathrm{O} 1 \mathrm{mM}, \mathrm{NaH}_{2} \mathrm{PO}_{4} \cdot 2 \mathrm{H}_{2} \mathrm{O} 1 \mathrm{mM}$, $\mathrm{CaCl}_{2} 2.5 \mathrm{mM}$, glucose $10 \mathrm{mM}$, and sodium pyruvate $1 \mathrm{mM}$ ) was added at the ratio of tissue to HBSS (mass: volume) of 1:3. After homogenization, the mixture was transferred to a $1.5-\mathrm{ml}$ EP tube. An equal volume of $32 \%$ dextran solution was then added, fully mixed, and centrifuged at $7245 \times g$ for $15 \mathrm{~min}$ at $4{ }^{\circ} \mathrm{C}$. The supernatant and the off-white brain tissues were removed. The brain microvessels at the bottom of the centrifuge tube were washed twice with 16\% dextran in HBSS buffer and then twice with HBSS buffer. After centrifugation, the pellet was resuspended in $500 \mu \mathrm{l}$ of HBSS buffer, and then 
filtered through 100- $\mu \mathrm{m}$ membrane filters. After another centrifugation, the pellet was added with RIPA buffer containing 1\% NP40 and protease inhibitor cocktail tablets and kept on ice for $30 \mathrm{~min}$ with vortexing for $15 \mathrm{~s}$ in every $10 \mathrm{~min}$. After centrifugation at $12,000 \times \mathrm{g}$ for $20 \mathrm{~min}$ at $4{ }^{\circ} \mathrm{C}$, the supernatant was collected, and protein expression was measured by western blot.

\section{Statistical analysis}

The data were expressed as the means \pm SD or means \pm SEM, as specifically indicated in the figure legends. Datasets were tested for normality distribution, and those passed the normality test were examined by one-way analysis of variance (ANOVA) with Tukey's post hoc tests by SPSS 21.0 software. $P$ values of $<0.05$ were considered to be statistically significant; $P<0.01$ was considered to be remarkably significant.

\section{Acknowledgements}

This work was supported by the National Natural Science Foundation of China [grant numbers 31400857, 31471035], the Youth Talent Foundation of Education Department of Hebei Province [grant number BJ2017005], and the Natural Science Foundation of Hebei Province [grant number C2019205273].

\section{Conflict of interest}

The authors declare that they have no conflict of interest.

\section{Publisher's note}

Springer Nature remains neutral with regard to jurisdictional claims in published maps and institutional affiliations.

The online version of this article (https://doi.org/10.1038/s41420-020-00346-3) contains supplementary material, which is available to authorized users.

Received: 18 August 2020 Accepted: 12 October 2020

Published online: 30 October 2020

\section{References}

1. Hare, D., Ayton, S., Bush, A. \& Lei, P. A delicate balance: Iron metabolism and diseases of the brain. Front. Aging Neurosci. 5, 34 (2013).

2. Todorich, B., Pasquini, J. M., Garcia, C. I., Paez, P. M. \& Connor, J. R. Oligodendrocytes and myelination: the role of iron. Glia 57, 467-478 (2009).

3. Yang, W. S. \& Stockwell, B. R. Ferroptosis: death by lipid peroxidation. Trends Cell Biol. 26, 165-176 (2016).

4. Lane, D. J. R., Ayton, S. \& Bush, A. I. Iron and Alzheimer's disease: an update on emerging mechanisms. J. Alzheimers Dis. 64, S379-S395 (2018).

5. James, S. A. et al. Iron, copper, and zinc concentration in abeta plaques in the APP/PS1 mouse model of Alzheimer's disease correlates with metal levels in the surrounding neuropil. ACS Chem. Neurosci. 8, 629-637 (2017).

6. Goedert, M. \& Spillantini, M. G. A century of Alzheimer's disease. Science $\mathbf{3 1 4}$ 777-781 (2006).

7. Meadowcroft, M. D., Connor, J. R., Smith, M. B. \& Yang, Q. X. MRI and histological analysis of beta-amyloid plaques in both human Alzheimer's disease and APP/PS1 transgenic mice. J. Magn. Reson. Imaging 29, 997-1007 (2009)

8. Bradley-Whitman, M. A. \& Lovell, M. A. Biomarkers of lipid peroxidation in Alzheimer disease (AD): an update. Arch. Toxicol. 89, 1035-1044 (2015).

9. Castellani, R. J. et al. Iron: the Redox-active center of oxidative stress in Alzheimer disease. Neurochem. Res. 32, 1640-1645 (2007).

10. Peters, D. G., Connor, J. R. \& Meadowcroft, M. D. The relationship between iron dyshomeostasis and amyloidogenesis in Alzheimer's disease: two sides of the same coin. Neurobiol. Dis. 81, 49-65 (2015).
11. Kwiatek-Majkusiak, J. et al. Relationships between typical histopathological hallmarks and the ferritin in the hippocampus from patients with Alzheimer's disease. Acta Neurobiol. Exp. (Wars.) 75, 391-398 (2015).

12. Lu, C. D. et al. Transferrin is responsible for mediating the effects of iron ions on the regulation of anterior pharynx-defective-1 alpha/beta and Presenilin 1 expression via PGE(2) and PGD(2) at the early stage of Alzheimer's Disease. Aging 10, 3117-3135 (2018).

13. Pinero, D. J., Hu, J. \& Connor, J. R. Alterations in the interaction between iron regulatory proteins and their iron responsive element in normal and Alzheimer's diseased brains. Cell. Mol. Biol. (Noisy-le.-Gd.) 46, 761-776 (2000).

14. Jan, A. T. et al. Perspective insights into disease progression, diagnostics, and therapeutic approaches in Alzheimer's disease: a judicious update. Front. Aging Neurosci. 9, 356 (2017).

15. Kupershmidt, L., Amit, T., Bar-Am, O., Youdim, M. B. \& Weinreb, O. The novel multi-target iron chelating-radical scavenging compound M30 possesses beneficial effects on major hallmarks of Alzheimer's disease. Antioxid. Redox Signal. 17, 860-877 (2012).

16. Guo, C. et al. Intranasal deferoxamine attenuates synapse loss via upregulating the P38/HIF-1alpha pathway on the brain of APP/PS1 transgenic mice. Front. Aging Neurosci. 7, 104 (2015).

17. Ganz, T. Hepcidin and iron regulation, 10 years later. Blood 117, 4425-4433 (2011).

18. Nemeth, E. et al. Hepcidin regulates cellular iron efflux by binding to ferroportin and inducing its internalization. Science 306, 2090-2093 (2004).

19. Nicolas, G. et al. The gene encoding the iron regulatory peptide hepcidin is regulated by anemia, hypoxia, and inflammation. J. Clin. Invest. 110, 1037-1044 (2002)

20. Ramey, G. et al. Hepcidin targets ferroportin for degradation in hepatocytes. Haematologica 95, 501-504 (2010).

21. Wang, S. M. et al. Role of hepcidin in murine brain iron metabolism. Cell. Mol. Life Sci. 67, 123-133 (2010).

22. Ding, $\mathrm{H}$. et al. Hepcidin is involved in iron regulation in the ischemic brain. PLOS ONE 6, e25324 (2011).

23. Raha-Chowdhury, R. et al. Expression and cellular localization of hepcidin mRNA and protein in normal rat brain. BMC Neurosci. 16, 24 (2015).

24. Raha, A. A., Vaishnav, R. A., Friedland, R. P., Bomford, A. \& Raha-Chowdhury, R. The systemic iron-regulatory proteins hepcidin and ferroportin are reduced in the brain in Alzheimer's disease. Acta Neuropathol. Commun. 1, 55 (2013).

25. Vela, D. The dual role of hepcidin in brain iron load and inflammation. Front. Neurosci. 12, 740 (2018).

26. Du, F., Qian, Z. M., Luo, Q., Yung, W. H. \& Ke, Y. Hepcidin suppresses brain iron accumulation by downregulating iron transport proteins in iron-overloaded rats. Mol. Neurobiol. 52, 101-114 (2015).

27. Zhou, Y. F. et al. Hepcidin protects neuron from hemin-mediated injury by reducing iron. Front. Physiol. 8, 332 (2017).

28. Zhang, F. L. et al. Impairment of hepcidin upregulation by lipopolysaccharide in the interleukin-6 knockout mouse brain. Front. Mol. Neurosci. 10, 367 (2017).

29. Urrutia, P. et al. Inflammation alters the expression of DMT1, FPN1 and hepcidin, and it causes iron accumulation in central nervous system cells. J. Neurochem. 126, 541-549 (2013).

30. Lu, L. N., Qian, Z. M., Wu, K. C., Yung, W. H. \& Ke, Y. Expression of iron transporters and pathological hallmarks of Parkinson's and Alzheimer's diseases in the brain of young, adult, and aged rats. Mol. Neurobiol. 54, 5213-5224 (2017).

31. McCarthy, R. C. \& Kosman, D. J. Glial cell ceruloplasmin and hepcidin differentially regulate iron efflux from brain microvascular endothelial cells. PLOS ONE 9, e89003 (2014)

32. McCarthy, R. C. \& Kosman, D. J. Mechanisms and regulation of iron trafficking across the capillary endothelial cells of the blood-brain barrier. Front. Mol. Neurosci. 8, 31 (2015).

33. Mills, E., Dong, X. P., Wang, F. \& Xu, H. Mechanisms of brain iron transport: insight into neurodegeneration and CNS disorders. Future Med. Chem. 2, 51-64 (2010).

34. Stepanichev, M. Y. et al. Amyloid-beta(25-35)-induced memory impairments correlate with cell loss in rat hippocampus. Physiol. Behav. 80, 647-655 (2004).

35. Yamaguchi, Y. \& Kawashima, S. Effects of amyloid-beta-(25-35) on passive avoidance, radial-arm maze learning and choline acetyltransferase activity in the rat. Eur. J. Pharmacol. 412, 265-272 (2001).

36. Wang, P. et al. Mitochondrial ferritin deletion exacerbates beta-amyloidinduced neurotoxicity in mice. Oxid. Med. Cell. Longev. 2017, 1020357 (2017). 
37. Shao, C. Y., Mirra, S. S., Sait, H. B., Sacktor, T. C. \& Sigurdsson, E. M. Postsynaptic degeneration as revealed by PSD-95 reduction occurs after advanced Abeta and tau pathology in transgenic mouse models of Alzheimer's disease. Acta Neuropathol. 122, 285-292 (2011)

38. Culmsee, C. \& Landshamer, S. Molecular insights into mechanisms of the cell death program: role in the progression of neurodegenerative disorders. Curr. Alzheimer Res. 3, 269-283 (2006).

39. Kim, E. K. \& Choi, E. J. Compromised MAPK signaling in human diseases: an update. Arch. Toxicol. 89, 867-882 (2015).

40. Giraldo, E., Lloret, A., Fuchsberger, T. \& Vina, J. Abeta and tau toxicities in Alzheimer's are linked via oxidative stress-induced p38 activation: protective role of vitamin E. Redox Biol. 2, 873-877 (2014).

41. Ryu, E. J. et al. PEP1glutaredoxin 1 protects against hippocampal neuronal cell damage from oxidative stress via regulation of MAPK and apoptotic signaling pathways. Mol. Med. Rep. 18, 2216-2228 (2018).

42. Wang, C. P. et al. Isoquercetin ameliorates cerebral impairment in focal ischemia through anti-oxidative, anti-inflammatory, and anti-apoptotic effects in primary culture of rat hippocampal neurons and hippocampal CA1 region of rats. Mol. Neurobiol. 54, 2126-2142 (2017).

43. Wu, J. R., Tuo, Q. Z. \& Lei, P. Ferroptosis, a recent defined form of critical cell death in neurological disorders. J. Mol. Neurosci. 66, 197-206 (2018).

44. Cheng, Y., Zak, O., Aisen, P., Harrison, S. C. \& Walz, T. Structure of the human transferrin receptor-transferrin complex. Cell 116, 565-576 (2004).

45. Gunshin, $\mathrm{H}$. et al. Cloning and characterization of a mammalian protoncoupled metal-ion transporter. Nature 388, 482-488 (1997).

46. De Domenico, I. et al. Hepcidin mediates transcriptional changes that modulate acute cytokine-induced inflammatory responses in mice. J. Clin. Investig. 120, 2395-2405 (2010).
47. Urrutia, P. J., Hirsch, E. C., Gonzalez-Billault, C. \& Nunez, M. T. Hepcidin attenuates amyloid beta-induced inflammatory and pro-oxidant responses in astrocytes and microglia. J. Neurochem. 142, 140-152 (2017).

48. Rouault, T. A. Post-transcriptional regulation of human iron metabolism by iron regulatory proteins. Blood Cells Mol. Dis. 29, 309-314 (2002).

49. Haider, L. et al. Multiple sclerosis deep grey matter: the relation between demyelination, neurodegeneration, inflammation and iron. J. Neurol. Neurosurg. Psychiatry 85, 1386-1395 (2014).

50. Vela, D. Hepcidin, an emerging and important player in brain iron homeostasis. J. Transl. Med. 16, 25 (2018).

51. Hofer, T. \& Perry, G. Nucleic acid oxidative damage in Alzheimer's diseaseexplained by the hepcidin-ferroportin neuronal iron overload hypothesis? J. Trace Elem. Med. Biol. 38, 1-9 (2016).

52. $\mathrm{Ma}$, J. et al. Different characteristics of hepcidin expression in $\mathrm{IL}-6+/+$ and $\mathrm{IL}-$ 6-/- neurons and astrocytes treated with lipopolysaccharides. Neurochem. Res. 43, 1624-1630 (2018).

53. Kruszewski, M. Labile iron pool: the main determinant of cellular response to oxidative stress. Mutat. Res. 531, 81-92 (2003).

54. Meng, X. et al. Specific gene expression in mouse cortical astrocytes is mediated by a $1740 \mathrm{bp}-$ GFAP promoter-driven combined adeno-associated virus 2/5/7/8/9. Neurosci. Lett. 593, 45-50 (2015).

55. You, L. H. et al. Astrocyte hepcidin is a key factor in LPS-induced neuronal apoptosis. Cell Death Dis. 8, e2676 (2017).

56. Wang, X., Sykes, D. B. \& Miller, D. S. Constitutive androstane receptor-mediated up-regulation of ATP-driven xenobiotic efflux transporters at the blood-brain barrier. Mol. Pharmacol. 78, 376-383 (2010).

57. Hartz, A. M., Bauer, B., Fricker, G. \& Miller, D. S. Rapid regulation of Pglycoprotein at the blood-brain barrier by endothelin-1. Mol. Pharmacol. $\mathbf{6 6}$ 387-394 (2004) 